I Simpósio Regional da Sociedade Brasileira de Geofisica
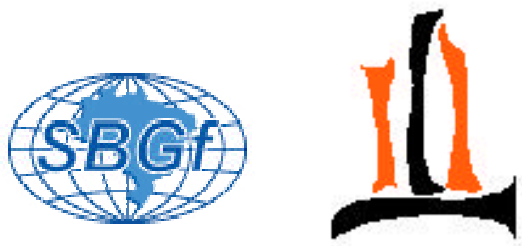

São Paulo 2004

\title{
Modelagem 2D das anomalias magnéticas no homoclinal da Serra do Curral
}

Natália Valadares de Oliveira, Maria Sílvia Carvalho Barbosa, Issamu Endo - DEGEO/EM/UFOP

\section{Copyright 2004, SBGf - Sociedade Brasileira de Geofísica}

Este texto foi preparado para a apresentação no I Simpósio de Geofísica da Sociedade Brasileira de Geofísica, São Paulo, 26-28 de setembro de 2004. Seu conteúdo foi revisado pela Comissão Tecno-científica do I SR-SBGf mas não necessariamente representa a opinião da SBGf ou de seus associados. E proibida a reprodução total ou parcial deste material para propósitos comerciais sem prévia autorização da SBGt.

\section{Resumo}

A análise integrada de dados magnetométricos e geológicos na região do homoclinal Curral, Quadrilátero Ferrífero - Minas Gerais permitiu modelar o arcabouço geológico através de programas de deconvolução Euler 2D e GM-SYS. O modelo obtido consiste na verificação das profundidades do embasamento, do gnaisse Souza Noschese e da geometria do homoclinal Curral.

\section{Introdução}

Dentre os diversos métodos geofísicos, a magnetometria é a mais usada em pesquisas que envolvem o arcabouço geológico e a prospecção mineral (Cordell \& Grauch 1985, Luiz \& Silva 1995, Mushayandebvu et al. 2001). A magnetometria opera no sentido de destacar as maiores e menores anomalias magnéticas das rochas, sem identificar o tipo de rocha, conforme a sua variação de susceptibilidade magnética e profundidade do corpo. Portanto, a geologia é essencial em qualquer método, seja ele geofísico, geoquímico, etc. Com base nos fundamentos da magnetometria é possível afirmar que o método é eficaz no reconhecimento geológico em subsuperfície através do mapeamento e delimitação da geometria 2D utilizando-se de uma camada-guia.

A área investigada localiza-se na porção noroeste do Quadrilátero Ferrífero (Qfe), Minas Gerais denominada de homoclinal da Serra do Curral (Figura 1). A estrutura da Serra do Curral é mais complexa que as demais estruturas de sinclinais e anticlinais do QFe e não há ainda um modelo evolutivo específico para esse segmento. O homoclinal Curral é mais conhecido pelo seu aspecto fisiográfico marcado por uma extensa cordilheira que se estende desde a Serra Piedade a NE até as imediações de Itatiaiaçu a SW. Apresenta-se como um homoclinal representado apenas pela aba SE invertida de um sinclinal. As camadas possuem mergulhos elevados e são comuns falhas de alto ângulo cortando as unidades do Supergrupo Minas que afloram em toda a serra (Endo 1997). O objetivo do presente trabalho é integrar dados geológicos e geofísicos com intuito de verificar um possível modelo geológico teórico para a região.

\section{Metodologia}

Os dados geofísicos aéreos utilizados, devidamente processados e tratados, possibilitaram a geração de mapas magnetométricos corrigido de IGRF (International Geomagnetic Reference Field) e segunda derivada. Gerou-se o perfil magnetométrico coincidente com a seção geológica afim de se obter a modelagem 2D através do programa GM-SYS, que utiliza os algoritmos descritos por Won \& Bevis (1987), onde as anomalias teóricas são calculadas a partir de um modelo poligonal. $O$ banco de dados do perfil magnetométrico foi convertido em arquivo ASCII para processar o perfil de deconvolução Euler. O algoritmo de deconvolução Euler 2D (Durrheim \& Cooper 1998) foi utilizado com intuito de mapear a profundidade média do topo do embasamento até quatro quilômetros. A modelagem consiste no ajuste da seção geológica, em subsuperfície, integrada ao perfil magnetométrico no programa GM-SYS, e a entrada do parâmetro de susceptibilidade magnética das unidades geológicas presentes de acordo com a bibliografia disponível (Sharma 1986, Telford et. al. 1990, Luiz \& Silva 1995). O mapa geológico e uma seção detalhada da área de estudo são fundamentais para aumentar a confiabilidade dos resultados.

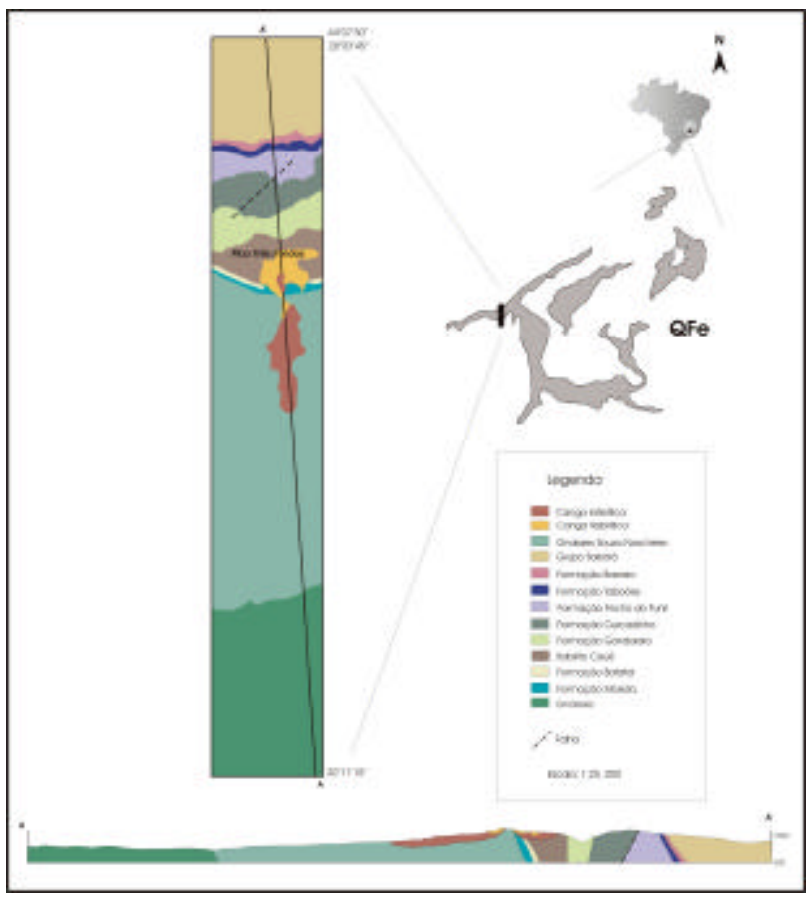

Figura 1 - Mapa geológico da região do homoclinal da Serra do Curral a ser investigada (Modificado de George Simmons, DNPM/USGS 1959). 


\section{Resultados}

Através do mapa magnetométrico corrigido de IGRF observaram-se anomalias negativas referentes à estrutura da Serra do Curral, onde a maior parte das unidades litológicas correspondem à metassedimentos de baixos valores magnéticos, com exceção da formação ferrífera Cauê. As anomalias de valores intermediários a positivos nas adjacências caracterizam as rochas graníticas e gnáissicas que representam o embasamento e o gnaisse Souza Noschese (Figura 2a). Já no mapa magnetomérico da segunda derivada, pode-se reconhecer as estruturas dobradas com direção NW-SE ao longo da área de estudo que estão vinculadas às fontes crustais mais rasas (Figura 2b).

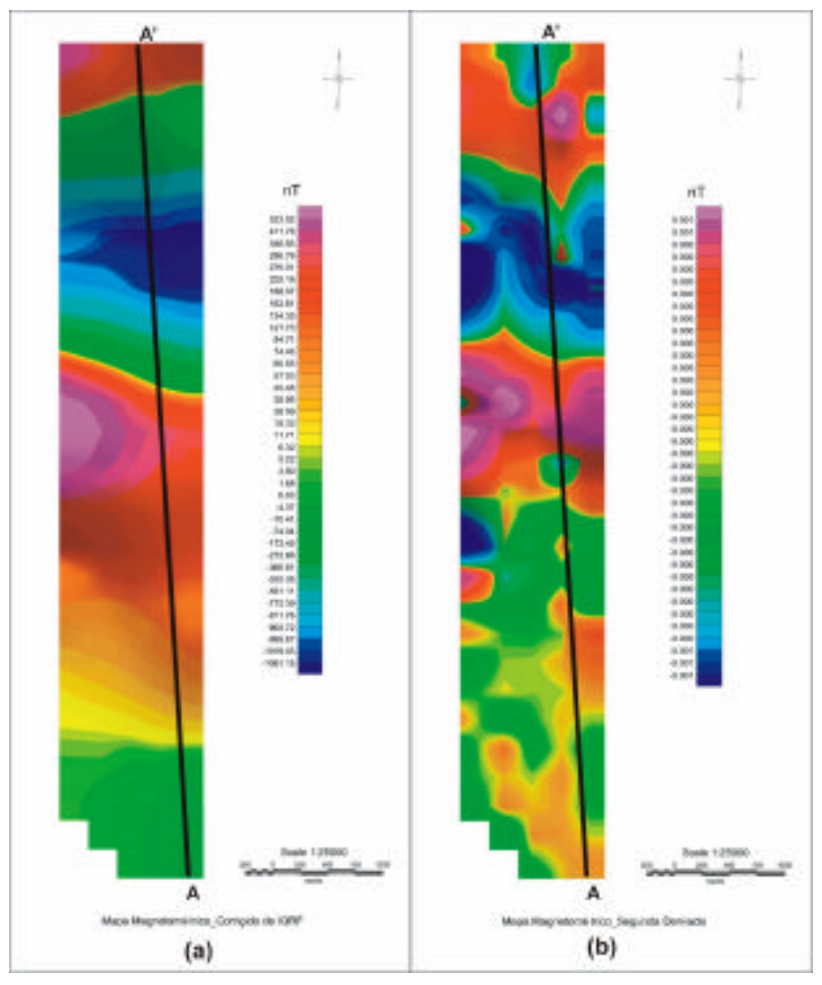

Figura 2: - Mapas Magnetométricos: a) Corrigido de IGRF; b) Segunda derivada; Perfil magnetométrico AA'.

A aplicação da deconvolução Euler 2D resultou na interpretação de um possível topo de embasamento e na determinação de contatos entre embasamento, gnaisse e metassedimentos. Na porção $\mathrm{N}$ do perfil foi possível ajustar em profundidade o topo de embasamento a $650 \mathrm{~m}$ em contato com a Formação Sabará, com as demais formações os contatos apresentam-se em profundidades que variam de 800 a $1900 \mathrm{~m}$. O ajuste da geologia em subsuperfície baseou-se, inicialmente na caracterização dos picos de anomalias. As diversas anomalias observadas em profundidade no gnaisse Souza Noschese deve-se, provavelmente, a intrusões máficas e zonas de cisalhamento observadas em superfície. A geometria do homoclinal foi analisada uma profundidade de até $2 \mathrm{~km}$ (Figura 3).
Como resultado integrado, tem-se um provável modelo geológico para a região do homoclinal da Serra do Curral (Figura 4). Pode-se inferir que o contato norte entre o embasamento e o gnaisse Souza Noschese encontra-se deslocado ao longo de zonas de cisalhamento, permitindo a intrusão de diques máficos e corpos graníticos com formação de auréolas metamórficas de contato nos xistos e filitos da Formação Sabará, em toda região de estudo. O contato entre o gnaisse Souza Noschese e o embasamento foi delimitado pela anomalias mais proeminentes. A formação ferrífera Cauê, fortemente magnetizada, encontra-se dobrada e as demais unidades apresentam contatos com mergulhos elevados, provavelmente devido a uma reativação das estruturas presentes.

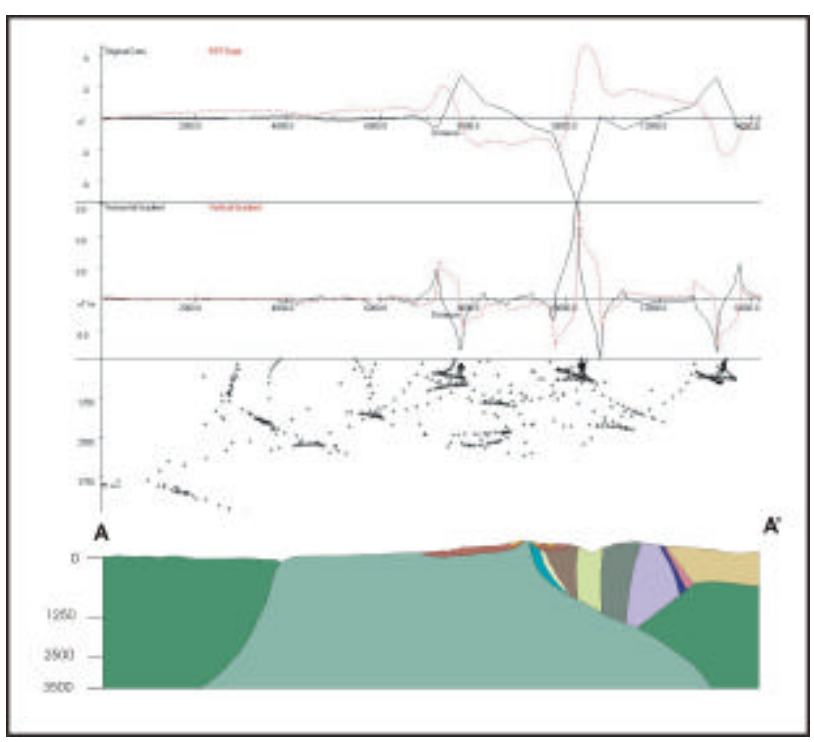

Figura 3 - Perfil geológico ajustado, em profundidade, ao perfil magnetométrico de deconvolução Euler $2 D$ da região.

\section{Discussão e Conclusões}

A deconvolução Euler auxiliou na interpretação preliminar para um modelo crustal a níveis mais rasos e a modelagem 2D permitiu a verificação deste modelo, onde este apresentou um bom ajuste (erro $=0.329 \%$ ) com os dados de magnetometria. Desta forma, foi possível adicionar informações de subsuperfície ao arcabouço geológico do homoclinal da Serra do Curral.

A região do $Q F e$, embora muito conhecida e estudada, apresenta o arcabouço geológico e a evolução tectônica complexos, resultando em modelos polifásicos e conflituosos entre si (e.g. Dossin et. al. 1992; Chauvet \& Menezes 1992; Chemale et. al. 1991; Chemale et. al. 1994; Endo 1997; Alkmim \& Marshak 1998; Hippertt \& Davis 2000), justamente pela falta de informações a níveis crustais que a geofísica pode oferecer. A complementação destas informações aos modelos existentes aumentará a confiabilidade dos mesmos. 


\section{Agradecimentos}

Os autores agradacem à CPRM pela liberação dos dados magnetométricos dos projetos Comig, Rio das Velhas e Brasil-Alemanha. Ao doutorando Luiz Gabriel S. de Oliveira pelas discussões.

\section{Referências}

Alkmim F. F. \& Marshak S. 1998: Transamazonian orogeny in the Southern São Francisco craton region, Minas Gerais, Brazil: evidence for Paleoproterozoic collision and collapse in the Quadrilátero Ferrífero. Precamb. Res., 90: 29-58.

Cordell, L. E. \& Grauch, V. T. S. 1985. Mapping basement magnetization zones from aeromagnetic data in the San Juan. In: Hinze W. J. (Ed). The utility of Regional Gravity and magnetic anomaly maps. SEG. 181197.

Chauvet A. \& Menezes M. 1992: Évolution structurale du sud du Craton São Francisco: implications sur les minéralisations auriferes de la région d' Ouro Preto, Brésil.C.R. Acad. Sci. Paris, Série II, 315: 495-501.

Chemale F. Jr.; Rosière C. A.; Endo I. 1991. Evolução tectônica do Quadrilátero Ferrífero, Minas Gerais: Um modelo. Pesquisas, 18: 104-127.

Chemale F. Jr.; Rosière C. A.; Endo, I. 1994. The tectonic evolution of the Quadrilátero Ferrífero, Minas Gerais, Brazil. Precamb. Res., 65:25-54.

DNPM/USGS. 1959. Mapa Geológico da metade sul da quadrícula do Fecho do Funil e metade norte da quadrícula Brumadinho, Minas Gerais Brasil.

Dossin I. A.; Dossin T. M.; Chauvet J.; Chemale Jr. F. 1992. Tectonique du Protérozoique supériuer au sud-est du Craton São Francisco (Minas Gerais, Brésil), C. R. Acad. Sci. Paris, Série II., 315: 629-636.

Durrheim R. J. \& Cooper G. J. R. 1998. EULDEP: A program for the Euler deconvolution of magnetic and gravity data. Computers \& Geosciences, 24:545-550.

Endo I. 1997. Regimes tectônicos do Arqueano e Proterozóico no interior da Placa Sanfranciscana: Quadrilátero Ferrífero e áreas adjacentes, Minas Gerias. Tese de Doutoramento, Instituto de Geociências, Universidade de São Paulo, São Paulo.

Hippertt J. F. \& Davis, B. 2000. Dome emplacement and formation of kilometre-scale-synclines in a granitegreenstone terrain (Quadrilátero Ferrífero, southeastern Brazil). Precamb. Res., 102: 99-121.

Luiz J. G. \& Silva L. M. C. 1995. Geofísica de Prospecção. Belém, Brasil.

Mushyandebvu, M. F., van Driel, P., Reid, A. B., Fairhead, J. D. 2001. Magnetic source parameters of 2-D structures using extended Euler deconvolution. Geophysics, 66: 814-823.

Sharma, P. V. 1986. Geophysical Methods in Geology. 2nd. ed., Amsterdam.

Telford, W. M., Geldart, L.P, Sheriff, R. E., Keys, D.A. 1990. Applied Geophysics. 2nd ed., Cambridge University Press, England.

Won I. J. \& Bevis M. 1987. Computing the gravitational and magnetic anomalies due to a polygon: Algorithms and Fortran subroutines. Geophysics, 53: 837-845. 


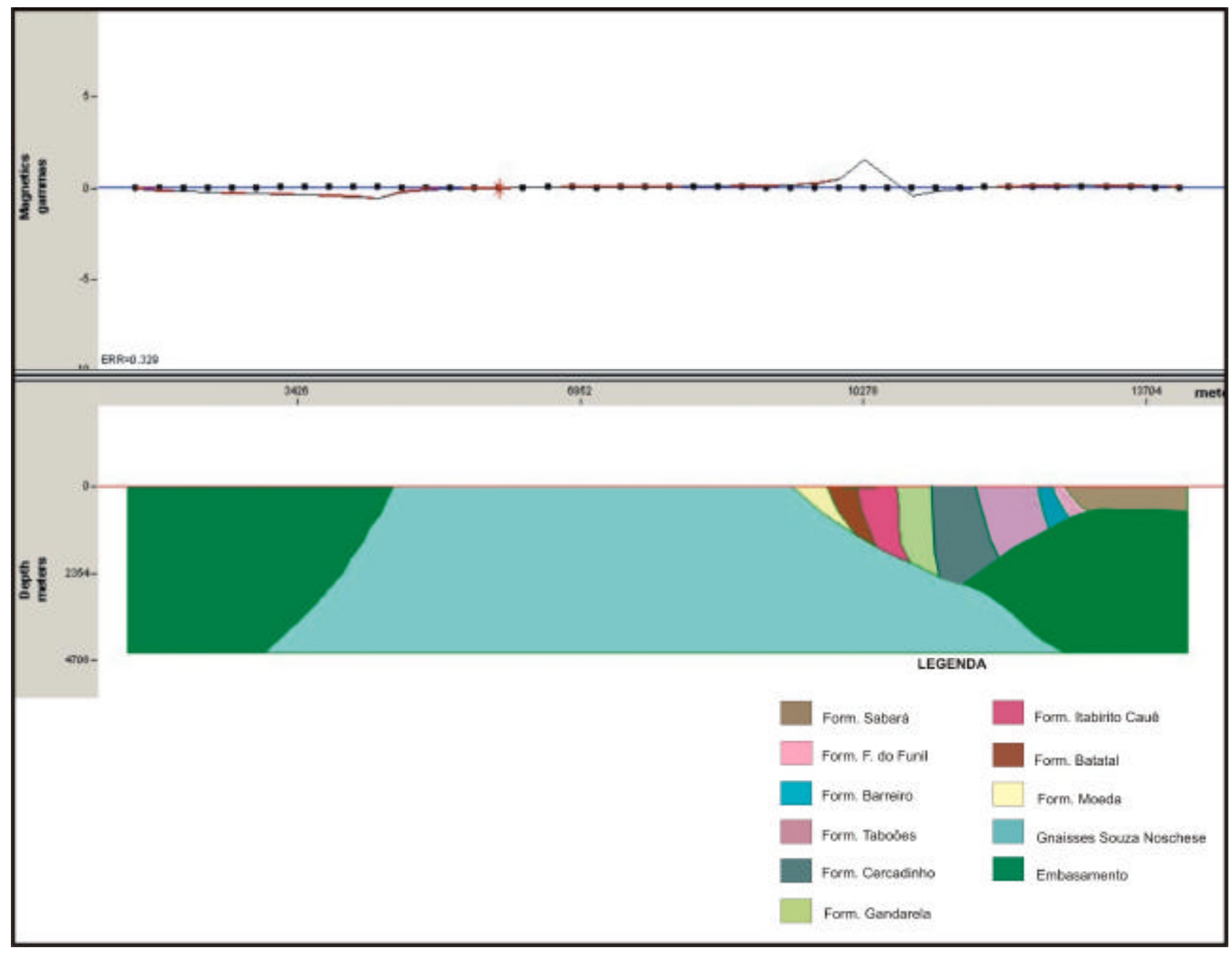

Figura 4: Resultado final da modelagem magnetométrica 2D no programa GM-SYS. 